\title{
PENGOLAHAN KONSENTRAT DESALINASI NUKLIR DENGAN KONSEP ZERO DISCHARGE DESALINATION UNTUK PULAU BANGKA
}

\author{
Erlan Dewita, Siti Alimah \\ Pusat Kajian Sistem Energi Nuklir (PKSEN)-BATAN \\ Jl. Kuningan Barat, Mampang Prapatan, Jakarta Selatan, 12710 \\ Phone/ Fax : (021) 5204243, E-mail : erland@batan.go.id
}

\begin{tabular}{|c|c|c|}
\hline Diterima & Diterima dalam bentuk revisi & Disetujui \\
\hline 16 Februari 2015 & 10 April 2015 & 24 April 2015 \\
\hline
\end{tabular}

\begin{abstract}
ABSTRAK
PENGOLAHAN KONSENTRAT DESALINASI NUKLIR DENGAN KONSEP ZERO DISCHARGE DESALINATION UNTUK PULAU BANGKA. Desalinasi nuklir merupakan proses untuk memisahkan garam terlarut dalam air laut dengan memanfaatkan panas nuklir. Konsentrat desalinasi merupakan salah satu masalah dalam desalinasi. Aliran konsentrat desalinasi yang dibuang langsung ke air laut dapat mempengaruhi kualitas air pantai dan memberikan dampak negatif pada biota yang berada di sekitar lokasi keluaran. Konsep ZDD (Zero Discharge Desalination) dapat diaplikasikan untuk meminimalkan dampak lingkungan. ZDD adalah konsep pengolahan limbah desalinasi menjadi garam dan produk kimia yang mempunyai nilai komersial. Penelitian bertujuan untuk memperoleh data awal pra-rancangan instalasi pengolahan konsentrat desalinasi di pulau Bangka. Metodologi yang digunakan adalah kajian literatur dan perhitungan dengan program excel. Hasil studi memperlihatkan bahwa produk utama adalah $\mathrm{NaCl}$ (garam farmasi) dan produk samping berupa cake $\mathrm{BaSO}_{4}, \mathrm{Mg}(\mathrm{OH})_{2}, \mathrm{BaCO}_{3}$.
\end{abstract}

Kata Kunci: desalinasi, nuklir, konsentrat, $\mathrm{ZDD}, \mathrm{BaSO}_{4}, \mathrm{Mg}(\mathrm{OH})_{2}, \mathrm{BaCO}_{3}, \mathrm{NaCl}$

\begin{abstract}
DESIGN OF NUCLEAR DESALINATION CONCENTRATE PLANT BY USING ZERO DISCHARGE DESALINATION CONCEPT FOR BANGKA ISLAND. Nuclear desalination is a process to separate salt of seawater by using nuclear energy. Desalination concentrate is a problem in nuclear desalination. Desalination concentrate is sometimes discharged directly into the seawater, therefore it can affects the water quality of beach and rise negative effects on the biota in the vicinity of the output. ZDD (Zero Discharge Desalination) concept can be applied to minimized environment impact. This study is conducted by using PWR type NPP as nuclear heat source and using ZDD concept to process desalination waste. $Z D D$ is a concept for processing of desalination concentrate into salt and chemical products which have economic values. Objectives of this study is to design nuclear desalination concentrate processing plant in Bangka Island. The methodology is literature assessment and calculation with excel programme. The results of this study shows that the main the products are $\mathrm{NaCl}$ (pharmaceutical salt) and cakes $\mathrm{BaSO}_{4}, \mathrm{Mg}(\mathrm{OH})_{2}, \mathrm{BaCO}_{3}$ as by products.
\end{abstract}

Keywords: desalination, nuclear, concentrate, $\mathrm{ZDD}, \mathrm{BaSO}_{4}, \mathrm{Mg}(\mathrm{OH})_{2}, \mathrm{BaCO}, \mathrm{NaCl}$ 


\section{PENDAHULUAN}

Sesuai dengan isi Peraturan Pemerintah RI No.79 Tahun 2014, tentang kebijakan energi nasional, Pemerintah telah menetapkan sasaran bauran energi primer optimal yaitu memberi kesempatan kepada sumber energi baru dan terbarukan (biomassa, nuklir, tenaga air, tenaga surya, tenaga angin) untuk berkontribusi minimal 23\% pada tahun 2025 dan 31\% pada tahun 2050. Kebijakan pemerintah tersebut memberi peluang dan tantangan terhadap penerapan dan pengembangan reaktor nuklir (PLTN) di Indonesia. Provinsi Kepulauan Bangka Belitung dipertimbangkan sebagai bakal calon tapak PLTN. Saat ini, provinsi tersebut merupakan salah satu daerah yang mengalami kekurangan pasokan listrik, karena PT. PLN (Persero) hanya mampu memasok energi listrik sebesar 52,3 persen. Masalah lain yang dihadapi provinsi tersebut adalah kebutuhan akan air bersih, hanya sekitar 54,14\% yang mendapatkan air bersih ${ }^{[1]}$. Oleh karena itu, sebagai usaha untuk mendukung program pemerintah dalam menyediakan kebutuhan listrik nasional dan untuk membantu provinsi Bangka Belitung dalam mengatasi kebutuhan listrik dan air bersih, maka perlu dilakukan studi pemanfaatan PLTN kogenerasi. PLTN kogenerasi selain untuk memproduksi listrik, panas sisa PLTN dapat dimanfaatkan untuk memasok panas proses desalinasi, sehingga PLTN kogenerasi dipertimbangkan selain dapat menambah nilai ekonomi PLTN juga dapat mengatasi defisit listrik dan air bersih di provinsi Kepulauan Bangka Belitung. Desalinasi merupakan proses memisahkan garam/mineral terlarut dalam air laut untuk memperoleh produk air bersih.

Terdapat beberapa teknologi desalinasi di dunia yang sudah dioperasikan secara komersial menggunakan beberapa tipe reaktor nuklir, seperti di Jepang, Pakistan dan Kazakhstan. Teknologi desalinasi tersebut adalah MSF, MED dan RO. Sedangkan di Indonesia, teknologi desalinasi sudah diterapkan di beberapa PLTU untuk memasok kebutuhan air bersih. Salah satu masalah dalam desalinasi nuklir adalah konsentrat desalinasi yang merupakan limbah multi komponen, jika tidak diolah dengan tepat dan dibuang langsung ke air laut dapat mempengaruhi kualitas air pantai dan memberikan dampak negatif pada spesies yang berada di sekitar lokasi keluaran. Pada pembuangan konsentrat langsung ke air laut, salinitas yang lebih besar akan mempunyai efek yang lebih besar terhadap komunitas bentos. Penipisan oksigen akibat aliran konsentrat dapat membinasakan organisme laut.

Saat ini terdapat berbagai metode manajemen konsentrat limbah desalinasi selain pembuangan ke permukaan air laut yaitu pembuangan di instalasi pengolahan limbah, pembuangan menggunakan land application, pembuangan dengan injeksi sumur dalam, pembuangan ke kolam penguapan, dan konsep ZLD (Zero Liquid Discharge) ${ }^{[2,3]}$. Suatu konsep pengolahan limbah desalinasi baru yang disebut ZDD (Zero Discharge Desalination)[4], saat ini telah dikembangkan yaitu mengolahnya menjadi garam dan produk kimia (gypsummagnesium hidroksida, magnesium hidroksida, natrium klorida, barium sulfat, barium karbonat,dan lain-lain yang mempunyai nilai komersial. Selain menghasilkan produk komersial, penggunaan konsep ZDD dapat mengurangi polusi yang berdampak terhadap organisme laut.

Tujuan penelitian adalah memperoleh data awal pra-rancangan instalasi pengolahan konsentrat desalinasi nuklir, studi kasus Pulau Bangka, yang merupakan salah satu bakal calon tapak PLTN di Indonesia. Metodologi yang digunakan adalah kajian literatur dan perhitungan dengan program excel. Hasil penelitian diharap dapat memberi masukan pengambil kebijakan untuk meminimalkan dampak lingkungan akibat pembuangan konsentrat desalinasi nuklir, guna mendukung terwujudnya PLTN pertama di Indonesia. 


\section{PENGOLAHAN KONSENTRAT DESALINASI NUKLIR DENGAN KONSEP ZDD}

Desalinasi merupakan proses produksi air bersih dengan umpan air laut, sumber energinya dapat berasal dari PLTN (PLTN kogenerasi). Pemanfaatan panas nuklir untuk proses desalinasi membutuhkan sistem kopling (antarmuka) antara reaktor nuklir dengan instalasi desalinasi, yang berupa loop antara. Oleh karena itu, diperlukan adanya Intermediate Heat Exchanger (IHX) yang berguna untuk tujuan keselamatan di mana dapat mencegah kemungkinan risiko kontaminasi radioaktif ke air produk atau mencegah salinasi ke pendingin sekunder PLTN ${ }^{[5]}$. Umur desain dari sistem kopling harus sepanjang umur desain proses nuklir dan proses desalinasi. Tekanan operasi dari IHX harus dijaga lebih tinggi, sehingga dalam kasus kebocoran pipa perpindahan panas pada sistem sekunder, arah kebocoran menuju ke sistem primer[6]. Pada instalasi desalinasi dengan menggunakan membran, karena hanya menggunakan listrik, maka tidak ada risiko kontaminasi radioaktif yang mencapai instalasi desalinasi melalui koneksi transfer energi.

Proses desalinasi selain memproduksi air bersih, juga menghasilkan konsentrat (brine) yang mengandung kadar garam tinggi. Brine merupakan konsentrat desalinasi dengan TDS lebih besar dari $36.000 \mathrm{mg} / \mathrm{L}[7]$. Pada umumnya, karakteristika dari konsentrat desalinasi secara umum adalah[8]:

- Salinitasnya lebih besar dari air umpan.

- Mengandung unsur-unsur yang terkandung dalam air umpan.

- Kualitas air konsentrat adalah spesifik lokasi karena air umpan juga spesifik lokasi.

- Konsentrat juga mengandung beberapa bahan kimia sisa pada waktu pengolahan awal, seperti asam sulfat, anti kerak, khlorin dan bahan dekhlorinasi.

Konsentrat desalinasi apabila dibuang secara langsung ke laut berdampak dapat merusak biota laut ${ }^{[9]}$, karena itu perlu dilakukan pengolahan agar konsentrat desalinasi yang dibuang ke laut memenuhi standar buangan limbah yang sudah ditentukan. Negara-negara di dunia sudah menggunakan beberapa metode untuk pembuangan konsentrat desalinasi. Sebagai gambaran, saat ini di Amerika Serikat sudah menggunakan beberapa metode pembuangan konsentrat, dan prosentase penggunaan diperlihatkan pada Gambar 1.

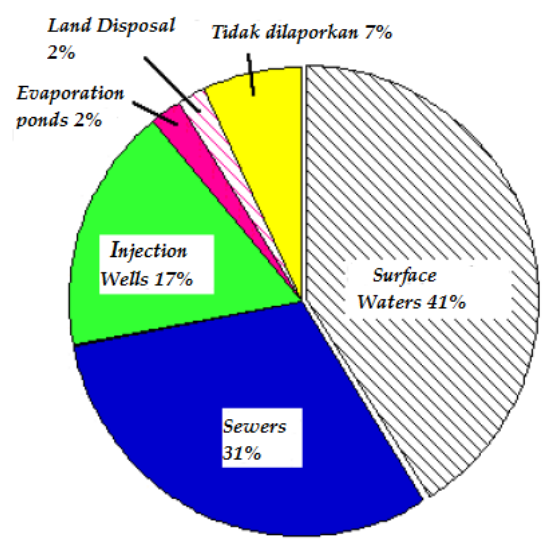

Gambar 1. Metode pengelolaan konsentrat (Status tahun 2006)[10].

Peningkatan salinitas terjadi akibat peningkatan konsentrasi unsur-unsur yang ada dalam air umpan dan konsentrasi bahan kimia yang ditambahkan. Namun demikian, karena konsentrat desalinasi mengandung sejumlah besar mineral yang mempunyai nilai komersial bila diekstrak, sehingga konsep ZDD perlu dipertimbangan untuk dikembangkan. 
ZDD merupakan konsep pengolahan konsentrat desalinasi menjadi garam dan produk kimia lain yang mempunyai nilai komersial. Konsep ZDD merupakan teknologi baru dan masih dalam penelitian dan pengembangan.

Pada dasarnya, konsep ZDD adalah hampir sama dengan sistem Zero Liquid Discharge (ZLD) tetapi berbeda dalam hal target output yang dihasilkan termasuk pemisahan garam menjadi produk yang dapat dijual[11]. Pada sistem ZLD dilakukan pemisahan garam, namun campuran garam tersebut dibuang ke land fill yang biaya kapital dan operasinya sangat mahal, pembuangan ke landfill dapat menyebabkan leaching kimia menuju air tanah jika desain landfill tidak tepat. Sedangkan konsep ZDD, digunakan untuk memisahkan dan mengambil garam-garam menjadi produk kimia yang mempunyai nilai komersial, selain dapat berdampak menghilangkan polusi konsentrat desalinasi atau ramah lingkungan. Selain itu, dengan konsep ZDD, tidak perlu untuk mengkonstruksi pipa non korosif metalik (dengan panjang 50-1000 m) dan diffuser pengeluaran effluent brine ke laut, sehingga dapat menghemat biaya perpipaan dan diffuser ${ }^{[2]}$.

Terdapat berbagai produk kimia yang dapat diambil dari konsentrat desalinasi. Namun demikian, produk kimia yang dapat diambil tergantung pada konsentrat desalinasi yang dihasilkan, dan dipengaruhi oleh komposisi kimia air laut umpan desalinasi. Pada penelitian ini diasumsikan umpan desalinasi berasal dari air laut Teluk Manggris di pulau Bangka, seperti terlihat dalam Tabel 1.

Tabel 1. Hasil Analisis Air Laut Teluk Manggris, Bangka Barat dengan Koordinat 105' 11' 3" E-10 99' S

\begin{tabular}{llll}
\hline No. & Parameter & Satuan & Hasil \\
\hline 1. & pH & - & 6,85 \\
2. & Konduktivitas & $\mu \mathrm{S} / \mathrm{cm}$ & 43,5 \\
3. & Total alkalinitas sbg CaCO3 & $\mathrm{ppm}$ & 200,85 \\
4. & TDS & $\mathrm{ppm}$ & 32804,00 \\
5. & Padatan tersuspensi & $\mathrm{ppm}$ & 48,20 \\
6. & Besi & $\mathrm{ppm}$ & 0,441 \\
7. & Kalsium $(\mathrm{Ca})$ & $\mathrm{ppm}$ & 433,74 \\
8. & Magnesium $(\mathrm{Mg})$ & $\mathrm{ppm}$ & 1938,63 \\
9. & Barium $(\mathrm{Ba})$ & $\mathrm{ppm}$ & 2522,57 \\
10. & Sodium $(\mathrm{Na})$ & $\mathrm{ppm}$ & 10992,96 \\
11. & Potasium $(\mathrm{K})$ & $\mathrm{ppm}$ & 327,87 \\
12. & Klorida $(\mathrm{Cl})$ & $\mathrm{ppm}$ & 16820,07 \\
13. & Sulfat $(\mathrm{SO} 4)$ & $\mathrm{ppm}$ & 3898,92 \\
14. & Bikarbonat & $\mathrm{ppm}$ & 244,60 \\
15. & SiO2 & $\mathrm{ppm}$ & 1,34 \\
16. & $\mathrm{~F}$ & $\mathrm{ppm}$ & $\mathrm{ttd}$ \\
\hline
\end{tabular}

Beberapa produk kimia dapat diperoleh melalui pengelolaan konsentrat dengan konsep ZDD seperti yang ditunjukkan pada Tabel 2.

Proses utama dalam konsep ZDD adalah pemurnian/pemisahan, evaporasi dan kristalisasi agar diperoleh garam dengan kemurnian tinggi. Diagram alir konsep ZDD secara umum diperlihatkan dalam Gambar 2. 
Tabel 2. Produk Potensial dari Pengelolaan Konsentrat Instalasi Desalinasi ${ }^{[7,0]}$

\begin{tabular}{|c|c|c|c|}
\hline Nama Produk & Aplikasi Pemasaran & Bentuk fisik & Harga,US \$ \\
\hline Gipsum- $\mathrm{Mg}(\mathrm{OH})_{2}$ & Remediasi tanah, aditif pupuk & Butiran halus & 150/ton \\
\hline $\mathrm{Mg}(\mathrm{OH})_{2}$ & $\begin{array}{l}\text { Pengelolaan air limbah, pertanian, aditif } \\
\text { bahan baku ternak }\end{array}$ & Butiran halus & $400 /$ ton \\
\hline $\mathrm{NaCl}$ & $\begin{array}{l}\text { Proses makanan, pertanian, bahan baku } \\
\text { garam farmasi. }\end{array}$ & Kristal & $35 /$ ton \\
\hline Garam Farmasi & $\begin{array}{l}\text { Kosmetik, infus, cairan dialisat, oralit, } \\
\text { obat-obatan dan shampo. }\end{array}$ & Butiran halus & $15 / \mathrm{kg}$ \\
\hline $\mathrm{CaCO}_{3}$ & $\begin{array}{l}\text { Pigmen pelapis kertas, pengisi cat plastik, } \\
\text { tinta dan produksi sealant. }\end{array}$ & $\begin{array}{l}\text { Butiran } \\
\text { halus, kristal }\end{array}$ & $300 /$ ton \\
\hline $\mathrm{Na}_{2} \mathrm{SO}_{4}$ & Industri pulp dan kertas & Kristal, & 130/ton \\
\hline $\mathrm{CaCl}_{2}$ & $\begin{array}{l}\text { Stabilisasi dasar jalanan (road stabilizer), } \\
\text { remediasi tanah, kontrol debu, proses } \\
\text { industri, aditif plastik dan lain-lain. }\end{array}$ & $\begin{array}{l}\text { Larutan } \\
\text { konsentrat }\end{array}$ & $220 /$ ton \\
\hline $\mathrm{BaSO}_{4}$ & $\begin{array}{l}\text { Digunakan untuk medis (memeriksa } \\
\text { sistem pencernaan pasien), pigmen putih } \\
\text { untuk cat, bahan pengisi pada industri } \\
\text { plastik. }\end{array}$ & Butiran halus & $128-250 /$ ton \\
\hline $\mathrm{BaCO}_{3}$ & $\begin{array}{l}\text { Digunakan untuk racun tikus, dalam } \\
\text { industri gelas, kertas, keramik, magnet, } \\
\text { elektroda, karet, cat. }\end{array}$ & Butiran halus & $400-500 /$ ton \\
\hline
\end{tabular}

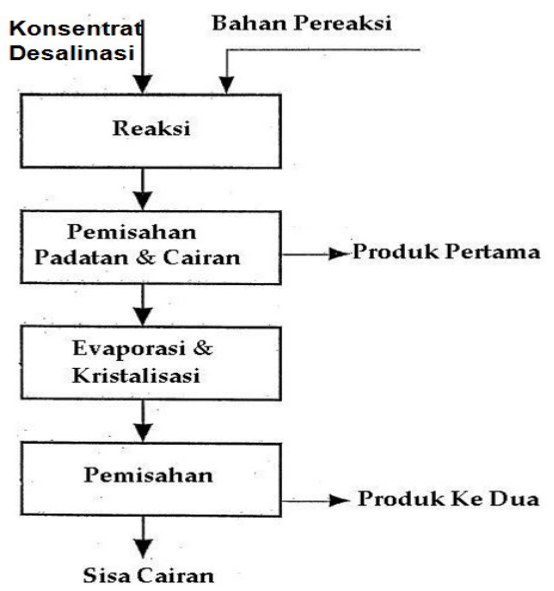

Gambar 2. Diagram Alir Konsep ZDD ${ }^{[12]}$.

Pengendapan dipengaruhi antara lain oleh $\mathrm{pH}$, waktu tinggal dan pengadukan. Dalam proses pengambilan garam, ketika air diuapkan dari konsentrat, maka garam akan diendapkan. Pada proses kristalisasi, setelah inti kristal terbentuk, kristal tidak langsung teramati karena ukurannya yang sangat kecil. Inti kristal ini akan tumbuh karena menempelnya molekul-molekul solute selapis demi selapis pada permukaan inti kristal. Oleh karena itu molekul solute harus berdifusi dari badan (bulk) larutan menuju ke permukaan kristal. Setelah ukuran kristal cukup besar, baru kemudian kristal itu dapat teramati dan mengendap. 


\section{PEMBAHASAN}

Air bersih dan brine merupakan produk dari proses desalinasi. Brine merupakan konsentrat yang mempunyai konsentrasi TDS tinggi $(>36,000 \mathrm{mg} / \mathrm{L})$ dan merupakan salah satu penyebab rusaknya lingkungan dan biota laut apabila dibuang secara langsung ke laut. Intensitas bahaya konsentrat terutama tergantung pada temperatur, TDS dan densitas. Jika densitas konsentrat tinggi, konsentrat akan menuju ke dasar laut dan membahayakan kehidupan laut, sebaliknya jika densitas rendah, maka konsentrat akan mengapung dan menyebabkan sedikit kerusakan. Oleh karena adanya efek yang merugikan terhadap lingkungan dan biota laut, diperlukan suatu teknologi yang dapat meminimalkan efek tersebut yaitu dengan konsep ZDD.

Sebagai umpan desalinasi digunakan air laut teluk Manggris, dengan hasil analisis seperti yang ditunjukkan pada Tabel 1. Hasil analisis menunjukkan bahwa kandungan ion $\mathrm{Na}$ dan $\mathrm{Cl}$ adalah paling tinggi sehingga produk utama dari penelitian ini garam $(\mathrm{NaCl})$. Namun, target produk utama dalam penelitian ini adalah garam farmasi. Selain harga garam farmasi lebih tinggi dibanding garam rakyat, kebutuhan garam dengan kemurnian tinggi masih banyak diimpor dari luar negeri, terutama garam farmasi dengan kemurnian rata-rata 99,5\%. Kebutuhan garam farmasi dalam negeri pada tahun 2003 mencapai 40.000 ton per tahun, yang semuanya dipenuhi dari impor dan pada tahun 2011 kebutuhan mencapai sekitar 50.000 ton $^{[13]}$.

Pada dasarnya, proses pengendapan terjadi tergantung pada jumlah maksimum zat terlarut dan hasil kali kelarutan ion-ion yang bergabung dalam larutan tersebut atau yang disebut dengan Quosien Reaksi (Q). Endapan akan terbentuk ketika hasil kali kelarutan ion-ionnya (Q) lebih besar dari pada harga hasil kali kelarutannya (Ksp). Semakin tinggi nilai Ksp suatu senyawa berarti senyawa semakin mudah larut dalam air dan jika nilai Ksp suatu senyawa semakin kecil maka senyawa makin sulit larut dalam air atau dengan kata lain lebih mudah mengendap. Diagram alir konsep ZDD yang direncanakan untuk proses pengolahan konsentrat desalinasi, dengan air umpan dari air laut Teluk Manggris Pulau Bangka diperlihatkan pada Gambar 3.

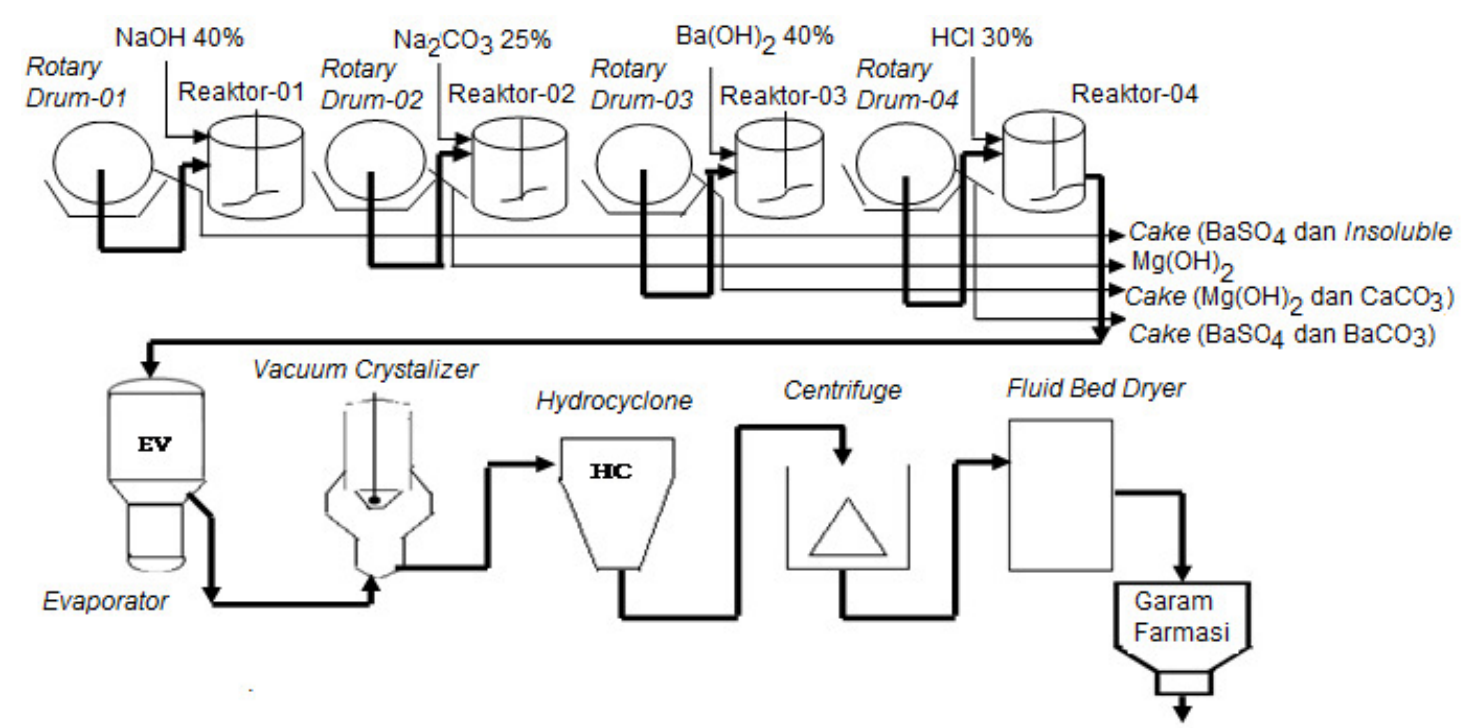

Gambar 3. Diagram Alir Konsep ZDD dengan Air Umpan Desalinasi dari Pulau Bangka. 
Peralatan utama yang digunakan untuk konsep ZDD adalah reaktor kimia, rotary drum, evaporator dan crystallizer, hydrocyclone dan centrifuge. Proses berlangsung dua tahap, yaitu tahap pemurnian brine water dan tahap pembuatan garam farmasi.

Pada proses pengolahan konsentrat ini, pemisahan dilakukan berdasarkan prinsip filtrasi dan sentifugasi dalam rotary drum ataupun centrifuge. Proses pengolahan diawali dengan filtrasi dan pengendapan konsentrat desalinasi yang masih mengandung padatan pengotor dalam Rotary Drum Vacuum Filter RD-01 sehingga diperoleh konsentrat yang bersih, cake ( $\mathrm{BaSO}_{4}$ dan padatan lain yang tidak larut), yang jika dimurnikan lebih lanjut, $\mathrm{BaSO}_{4}$ dapat dimanfaatkan sebagai produk samping. Padatan $\mathrm{BaSO}_{4}$ ini sebenarnya sudah terbentuk pada saat proses evaporasi pada proses desalinasi, hal ini terjadi karena arus konsentrat yang keluar dari instalasi desalinasi merupakan larutan lewat jenuh akibat proses evaporasi. Selanjutnya dengan filtrasi dan sentrifugasi dalam rotary drum maka endapan akan terpisah. Filtrat yang keluar dari RD-01 dimasukkan dalam Mixer Reaktor-01, dan dilakukan penambahan $\mathrm{NaOH}$ sehingga diperoleh endapan $\mathrm{Mg}(\mathrm{OH})_{2}$. Endapan $\mathrm{Mg}(\mathrm{OH})_{2}$ dipisahkan dengan menggunakan RD-02 dan sentrifugasi.

Filtrat keluaran RD-02 selanjutnya dimasukkan ke dalam Mixer Reaktor-02, dan dengan penambahan larutan $\mathrm{Na}_{2} \mathrm{CO}_{3}$ akan diperoleh $\mathrm{Mg}(\mathrm{OH})_{2}$ dan $\mathrm{CaCO}_{3}$, selanjutnya endapan dipisahkan dari RD-03. Selanjutnya filtrat RD-03 diumpankan ke Mixer Reaktor-03 untuk memperoleh $\mathrm{BaSO}_{4}$ dan $\mathrm{BaCO}_{3}$ dan dilakukan pemisahan dalam $\mathrm{RD}-04$. Filtrat keluaran RD-04 selanjutkanya dinetralisasi dengan $\mathrm{HCl}$ dalam Mixer Reaktor-04. Hasil netralisasi adalah larutan $\mathrm{NaCl}$ yang selanjutnya dipekatkan dalam evaporator dan dikristalkan dalam kristalizer dan selanjutnya diumpankan dalam hidrosiklon untuk dipisahkan kristal dan cairannya. Produk selanjutnya dikeringkan dalam fluid bed dryer. Komposisi konsentrat dapat dihitung berdasar asumsi seperti terlihat dalam Gambar 4. Pasokan air Bangka Belitung dari desalinasi diasumsikan 66.000 m³/hari.

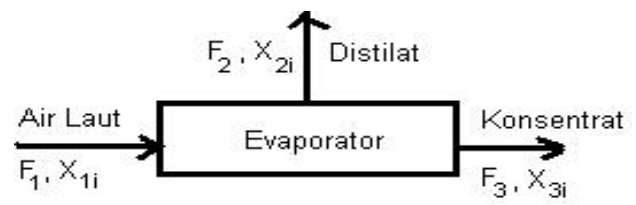

\section{Gambar 4. Diagram Alir Perhitungan Neraca Massa.}

$\mathrm{F}_{2}=66.000 \mathrm{~m}^{3} / \mathrm{hari}=2.750 \mathrm{~m}^{3} / \mathrm{jam}$, sehingga persamaan neraca massa total di evaporator :

$$
F_{1}=F_{2}+F_{3}
$$

Persamaan neraca massa komponen di evaporator :

$$
F_{1} \cdot x_{1}=F_{2} \cdot x_{2}+F_{3} \cdot x_{3}
$$

Karena distilat tidak mengandung garam, maka $x_{2}=0$, sehingga :

$$
x_{3}=\frac{F_{1} x_{2}}{F_{2}}
$$

Karena $F_{3}=F_{1}-F_{2}$, maka persamaan (3) menjadi :

$$
x_{3}=\frac{F_{1} \times x_{1}}{F_{1}-F_{z}}
$$

Pada studi ini, penguapan air di evaporator didesain 40\% agar beban panas yang dibutuhkan untuk menguapkan air tidak terlalu besar. Air yang menguap ini kemudian menjadi distilat.

- Air laut yang diperlukan $=F_{1}=\frac{100}{40} \times 2.750=6.875 \mathrm{~m}^{3} / \mathrm{jam}$

- Konsentrat $=\mathrm{F}_{3}=6.875-2.750=4.125 \mathrm{~m}^{3} / \mathrm{jam}$ 
Densitas air laut $=1024 \mathrm{~kg} / \mathrm{m}^{3[14]}$, densitas distilat $=983 \mathrm{~kg} / \mathrm{m}^{3}$ dan densitas konsentrat $=1043$ $\mathrm{kg} / \mathrm{m}^{3}$.

Berdasar perhitungan di atas, maka diperoleh prosentase massa konsentrat seperti terlihat pada Tabel 3.

Tabel 3. Komposisi dan Jumlah Konsentrat Desalinasi

\begin{tabular}{cccc}
\hline & \multicolumn{3}{c}{ Konsentrat dari unit desalinasi $=$ umpan pabrik garam } \\
\cline { 2 - 4 } Komponen & massa(kg/jam) & mol(kmol/jam) & $\%$ massa \\
$\mathrm{NaCl}$ & 142.687 & 2.441 & 3,27 \\
$\mathrm{MgCl}_{2}$ & 54.234 & 570 & 1,24 \\
$\mathrm{CaCl}_{2}$ & 8.507 & 77 & 0,19 \\
$\mathrm{BaCl}_{2}$ & 0 & 0 & 0,0 \\
$\mathrm{KCl}$ & 49 & 1 & 0,00 \\
$\mathrm{BaSO}_{4}$ & 30.291 & 130 & 0,69 \\
$\mathrm{NaHCO}_{3}$ & 2.381 & 28 & 0,05 \\
$\mathrm{Na}_{2} \mathrm{SO}_{4}$ & 22.324 & 157 & 0,51 \\
$\mathrm{H}_{2} \mathrm{O}$ & 4.103 .423 & 227.775 & 94,02 \\
$\mathrm{Insoluble}$ & 350 & 0 & 0,01 \\
\hline Total & 4.364 .246 & $\mathbf{2 3 1 . 1 7 8}$ & $\mathbf{1 0 0 , 0 0}$ \\
\hline
\end{tabular}

Berdasar Tabel 3, jumlah BaSO4 = $130 \mathrm{kmol} / \mathrm{jam}$, sehingga jumlah mol Ba2 $+=130 \mathrm{kmol} / \mathrm{jam}$. Jumlah mol SO4 2- $=$ mol BaSO4 + mol Na2SO4 $=130+157=287 \mathrm{kmol} / \mathrm{jam}$

$$
\begin{aligned}
& {\left[\mathrm{Ba}^{2+}\right]=\text { mol Ba} / \text { Volume }=\frac{130 \mathrm{kmol} / \mathrm{jam} \times 1024 \mathrm{~kg} / \mathrm{m} 3}{(4364246,88 \mathrm{~kg} / \mathrm{jam})}=0,0305 \mathrm{M}} \\
& {\left[\mathrm{SO}_{4}{ }^{2-}\right]=\frac{287 \mathrm{kmol} / \mathrm{jam} \times 1024 \mathrm{~kg} / \mathrm{m} 3}{(4364246,88 \mathrm{~kg} / \mathrm{jam})}=0,06734 \mathrm{M}} \\
& \mathrm{Q}=\left[\mathrm{Ba}^{2+}\right]\left[\mathrm{SO}_{4}{ }^{2}\right]=0,0305 \times 0,06734=0,002054 \text { dan } \mathrm{Ksp} \mathrm{BaSO}_{4}=1,0.10^{-10[15]},
\end{aligned}
$$

karena $\mathrm{Q}>\mathrm{Ksp}$, maka $\mathrm{BaSO}_{4}$ akan mengendap

$$
\begin{aligned}
& \mathrm{Ba}^{2+}+\mathrm{SO}_{4}^{2-} \rightarrow \mathrm{BaSO}_{4} \quad \mathrm{~K}=1 / \mathrm{Ksp}^{2} \\
& {\left[\mathrm{Ba}^{2+}\right] \text { awal }=0,0305 \mathrm{M} \text { dan }\left[\mathrm{SO}_{4}{ }^{2-}\right] \text { awal }=0,06734 \mathrm{M} \text {, asumsi yang bereaksi }=x}
\end{aligned}
$$

Maka $\left[\mathrm{Ba}^{2+}\right]$ akhir $=(0,0305-\mathrm{x}) \mathrm{M}$ dan $\left[\mathrm{SO}_{4}{ }^{2}\right]$ akhir $=(0,06734-\mathrm{x}) \mathrm{M}$

$\mathrm{Ksp}=\left[\mathrm{Ba}^{2+}\right]\left[\mathrm{SO}^{2-}\right]=1,0.10^{-10}$, sehingga Ksp $=[0,0305-\mathrm{x}][0,06734-\mathrm{x}]=1,0.10^{-10}$ Terlihat nilai Ksp sangat kecil, dan terhitung hampir $100 \% \mathrm{Ba}^{2+}$ terendapkan Jika nilai $\mathrm{x}=0,0305 \mathrm{M}$, maka seluruh $\mathrm{Ba}^{2+}$ mengendap dalam bentuk $\mathrm{BaSO}_{4}$.

$$
\text { Ion } \mathrm{SO}_{4}{ }^{2-} \text { sisa }=0,06734-0,0305=0,03684 \mathrm{M}
$$

Jika dikonversikan ke mol lagi, maka [ $\left.\mathrm{SO}_{4}{ }^{2-}\right]$ sisa $=$

$$
\frac{(4364246,88 \mathrm{~kg} / \mathrm{jam}) \times 0,03684 \mathrm{kmol} / \mathrm{m} 3}{1024 \mathrm{~kg} / \mathrm{m} 3}=157 \mathrm{kmol} / \mathrm{jam}
$$

Perhitungan untuk pengendapan lainnya dilakukan dengan cara yang sama. 
Dalam Tahap I, pengendapan sebagian $\mathrm{Mg}^{2+}$ dilakukan dengan penambahan $\mathrm{NaOH}$. Neraca massa keluar filter I, diperlihatkan dalam Tabel 4.

Tabel 4. Neraca Massa Keluar Filter I

\begin{tabular}{|c|c|c|c|c|}
\hline & \multicolumn{2}{|c|}{ Feed=keluar vacuum filter I } & \multicolumn{2}{|c|}{ Cairan $\mathrm{NaOH} 40 \%$} \\
\hline Komponen & massa $(\mathrm{kg} / \mathrm{jam})$ & $\mathrm{mol}(\mathrm{kmol} / \mathrm{jam})$ & $\operatorname{massa}(\mathrm{kg} / \mathrm{jam})$ & $\mathrm{mol}(\mathrm{kmol} / \mathrm{jam})$ \\
\hline $\mathrm{NaCl}$ & 142015 & 2430 & 0 & 0 \\
\hline $\mathrm{MgCl}_{2}$ & 53979 & 567 & 0 & 0 \\
\hline $\mathrm{CaCl}_{2}$ & 8467 & 76 & 0 & 0 \\
\hline $\mathrm{BaCl}_{2}$ & 0 & 0 & 0 & 0 \\
\hline $\mathrm{KCl}$ & 49 & 1 & 0 & 0 \\
\hline $\mathrm{BaSO}_{4}$ & 0 & 0 & 0 & 0 \\
\hline $\mathrm{NaHCO}_{3}$ & 2369 & 28 & 0 & 0 \\
\hline $\mathrm{Na}_{2} \mathrm{SO}_{4}$ & 22219 & 156 & 0 & 0 \\
\hline $\mathrm{H}_{2} \mathrm{O}$ & 4084080 & 226701 & 4899 & 272 \\
\hline Insoluble & 0 & 0 & 0 & 0 \\
\hline $\mathrm{Na}_{2} \mathrm{CO}_{3}$ & 0 & 0 & 0 & 0 \\
\hline $\mathrm{NaOH}$ & 0 & 0 & 3266 & 81,66 \\
\hline $\mathrm{Ba}(\mathrm{OH})_{2}$ & 0 & 0 & 0 & 0 \\
\hline $\mathrm{CaCO}_{3}$ & 0 & 0 & 0 & 0 \\
\hline $\mathrm{MgCO}_{3}$ & 0 & 0 & 0 & 0 \\
\hline $\mathrm{BaCO}_{3}$ & 0 & 0 & 0 & 0 \\
\hline $\mathrm{BaSO}_{4}$ & 0 & 0 & 0 & 0 \\
\hline $\mathrm{Mg}(\mathrm{OH})_{2}$ & 0 & 0 & 0 & 0 \\
\hline $\mathrm{HCl}$ & 0 & 0 & 0 & 0 \\
\hline $\mathrm{Ca}(\mathrm{OH})_{2}$ & 0 & 0 & 0 & 0 \\
\hline TOTAL & 4313178 & 229959 & 8166 & 354 \\
\hline
\end{tabular}

Pada Tabel 4, terlihat adanya ion $\mathrm{Mg}^{2+}$ dalam bentuk $\mathrm{MgCl}_{2}$, dengan penambahan $\mathrm{NaOH}$ dapat diendapkan dalam bentuk $\mathrm{Mg}(\mathrm{OH})_{2}$. Namun, ada batasan jumlah $\mathrm{NaOH}$ yang ditambahkan agar tidak terbentuk $\mathrm{Ca}(\mathrm{OH})_{2}$. $\mathrm{K}=\mathrm{Ksp}$ adalah konstanta keseimbangan, sedang pada reaksi sebaliknya $\mathrm{K}$ adalah $1 / \mathrm{Ksp}$

$$
\begin{array}{ll}
\mathrm{Ca}^{2+}+2 \mathrm{OH}^{-} \rightarrow \mathrm{Ca}(\mathrm{OH})_{2} & \mathrm{~K}=1 / \mathrm{KspCa}(\mathrm{OH})_{2} \\
\mathrm{Mg}^{2+}+2 \mathrm{OH}^{-} \rightarrow \mathrm{Mg}(\mathrm{OH})_{2} & \mathrm{~K}=1 / \mathrm{KspMg}(\mathrm{OH})_{2} \\
& \\
\mathrm{Ca}(\mathrm{OH})_{2} \rightarrow \mathrm{Ca}+2 \mathrm{OH} & \mathrm{K}=\mathrm{KspCa}(\mathrm{OH}) 2=7,9 \mathrm{E}-06 \\
\mathrm{Mg}(\mathrm{OH})_{2} \rightarrow \mathrm{Mg}+2 \mathrm{OH} & \mathrm{K}=\mathrm{KspMg}(\mathrm{OH})_{2}=1,5 \mathrm{E}-11
\end{array}
$$

Jumlah mol Ca${ }^{2+}=76 \mathrm{kmol} / \mathrm{jam}$ dan $\mathrm{Mg}^{2+}=567 \mathrm{kmol} / \mathrm{jam}$.

Setelah penambahan $\mathrm{NaOH} 40 \%$, $\left[\mathrm{Ca}^{2+}\right]$ dan $\left[\mathrm{Mg}^{2+}\right]$ berubah. Penambahan $\mathrm{OH}^{-}$pada $\mathrm{Ca}^{2+}$ dibatasi agar ion Ca tidak sampai mengendap maka:

$$
\begin{aligned}
& \mathrm{Ksp} \mathrm{Ca}(\mathrm{OH})_{2}=[\mathrm{Ca}][\mathrm{OH}]^{2} \\
& {[\mathrm{OH}]=(\mathrm{Ksp} /[\mathrm{Ca}])^{0.5} } \\
& {\left[\mathrm{Ca}^{2+}\right]=\text { mol Ca }{ }^{2+} / \text { Volum }=\frac{76 \mathrm{kmol} / \mathrm{jam} \times 1024 \mathrm{~kg} / \mathrm{m} 3}{4313178 \mathrm{~kg} / \mathrm{jam}}=0,0181 \mathrm{M} }
\end{aligned}
$$


Jadi maksimal $[\mathrm{OH}]$ ditambahkan $=(7,9 \mathrm{E}-6 /[0,0181])^{\wedge} 0,5=0,021 \mathrm{M}$

Dengan penambahan $0,019 \mathrm{M}$ maka akan terjadi pengendapan $\mathrm{Mg}(\mathrm{OH})_{2}$, dengan cara yang sama dapat diketahui ion $\mathrm{Mg}^{2+}$ yang mengendap.

$$
\begin{aligned}
& \mathrm{Mg}^{2+}+2 \mathrm{OH}^{-} \rightarrow \mathrm{Mg}(\mathrm{OH})_{2} \quad \mathrm{~K}=1 / \mathrm{Ksp} \\
& \mathrm{Mg}^{2+} \text { awal }=\frac{567 \mathrm{kmol} / \mathrm{jam} \times 1024 \mathrm{~kg} / \mathrm{m} 3}{4313178 \mathrm{~kg} / \mathrm{jam}}=0,1343 \mathrm{M} \\
& \mathrm{OH}^{-} \text {awal }=0,019 \mathrm{M} \text {, asumsi yang bereaksi }=\mathrm{x} \\
& {\left[\mathrm{Mg}^{2+}\right] \text { akhir }=(0,1343-\mathrm{x}) \mathrm{M} \text { dan }[\mathrm{OH}-\text { akhir }=(0,019-2 \mathrm{x}) \mathrm{M}} \\
& \mathrm{Ksp}^{-}\left[\mathrm{Mg}^{2+}\right][\mathrm{OH}]^{\wedge} 2=1,8.10^{-11[10]}, \text { Sehingga }=>[0,1343-\mathrm{x}][0,019-2 \mathrm{x}]^{\wedge} 2=1,8.10^{-11}
\end{aligned}
$$

Terlihat nilai Ksp sangat kecil dan terhitung hampir $100 \%$ OH bereaksi dan membentuk endapan $\mathrm{Mg}(\mathrm{OH})_{2}$. Jika nilai $(2 \mathrm{x})=0,019 \mathrm{M}$, maka seluruh $\mathrm{OH}$ mengendap dalam bentuk $\mathrm{Mg}(\mathrm{OH})_{2} . \mathrm{Mg}^{2+}$ sisa adalah 0,1343-0,019/2 =0,1248 M, jika dikonversi

$$
\frac{(4313178 \mathrm{~kg} / \mathrm{jam}) \times 0,1248 \mathrm{kmol} / \mathrm{m} 3}{1024 \mathrm{~kg} / \mathrm{m} 3}=526 \mathrm{kmol} / \mathrm{jam}
$$

Dengan cara perhitungan yang sama, maka akan diketahui jumlah produk $\mathrm{CaCO}_{3} \downarrow, \mathrm{BaSO}_{4} \downarrow$ $\mathrm{BaCO}_{3} \downarrow$ dan $\mathrm{NaCl}$, seperti terlihat dalam Tabel 5 .

Pengendapan $\mathrm{Ca}^{2+}$ dalam $\mathrm{CaCl}_{2}$ dan $\mathrm{Ba}^{2+}$ dalam $\mathrm{BaCl}_{2}$ dengan penambahan larutan $\mathrm{Na}_{2} \mathrm{CO}_{3}$. Namun karena $\mathrm{BaCl}_{2}=0$ maka yang terendapkan hanya $\mathrm{Ca}^{2+}$. Endapan $\mathrm{CaCO}_{3}$ diperoleh dari hasil reaksi $\mathrm{Ca}^{2+}$ dengan larutan $\mathrm{Na}_{2} \mathrm{CO}_{3} 25 \%$, reaksi yang terjadi :

$\mathrm{Na}_{2} \mathrm{CO}_{3}+\mathrm{CaCl}_{2} \rightarrow 2 \mathrm{NaCl}+\mathrm{CaCO}_{3}(\mathrm{~s}) \downarrow$

$\mathrm{SO}_{4}{ }^{2-}$ dalam $\mathrm{Na}_{2} \mathrm{SO}_{4}$ dan $\mathrm{CO}_{3}{ }^{2-}$ dalam $\mathrm{NaHCO}_{3}$ dengan penambahan larutan $\mathrm{Ba}(\mathrm{OH})_{2}$ akan mengendapkan $\mathrm{BaSO}_{4(\mathrm{~s}) \downarrow}$ dan $\mathrm{BaCO}_{3(\mathrm{~s})} \downarrow$, reaksi yang terjadi:

$$
\begin{aligned}
& \mathrm{Ba}(\mathrm{OH})_{2}+\mathrm{Na}_{2} \mathrm{SO}_{4} \rightarrow 2 \mathrm{NaOH}+\mathrm{BaSO}_{4}(\mathrm{~s}) \downarrow \\
& \mathrm{Ba}(\mathrm{OH})_{2}+\mathrm{NaHCO}_{3} \rightarrow \mathrm{NaOH}+\mathrm{H}_{2} \mathrm{O}+\mathrm{BaCO}_{3}(\mathrm{~s}) \downarrow
\end{aligned}
$$

Seperti diketahui, karena sebagian besar ion yang ada dalam bentuk $\mathrm{Na}$ dan $\mathrm{Cl}$, maka akan terbentuk garam $\mathrm{NaCl}$. Pembentukan garam $\mathrm{NaCl}$ ini dilakukan dengan menggunakan evaporator, kristalizer dan dipekatkan lebih lanjut menggunakan centrifuge.

Tabel 5. Komposisi Produk Akhir

\begin{tabular}{lcc}
\hline & \% massa & kg/jam \\
\hline $\mathrm{NaCl}$ & 99,98922 & 154073,6435 \\
$\mathrm{MgCl}_{2}$ & 0,00006 & 0,0966 \\
$\mathrm{CaCl}_{2}$ & 0,00001 & 0,0163 \\
$\mathrm{BaCl}_{2}$ & 0,00005 & 0,0742 \\
$\mathrm{KCl}$ & 0,00062 & 0,9481 \\
$\mathrm{NaHCO}_{3}$ & 0,00000 & 0,0046 \\
$\mathrm{Na}_{2} \mathrm{SO}_{4}$ & 0,00003 & 0,0429 \\
$\mathrm{Na}_{2} \mathrm{CO}_{3}$ & 0,00001 & 0,0157 \\
$\mathrm{H}_{2} \mathrm{O}$ & 0,01000 & 15,4072 \\
\hline $\mathrm{TOTAL}$ & 100 & $154.090,2491$ \\
\hline
\end{tabular}




\section{KESIMPULAN}

Pengolahan konsentrat desalinasi menggunakan konsep ZDD ditinjau dari aspek teknis dan konservasi lingkungan merupakan konsep yang potensi dikembangkan. Karena, selain meminimalkan polusi akibat tingginya salinitas konsentrat, juga dapat diolah menjadi diperoleh produk yang bernilai ekonomi. Pada hasil studi diperoleh produk komersial hasil pengolahan konsentrat desalinasi dengan konsep ZDD adalah $\mathrm{NaCl}$ (garam farmasi) dan cake $\mathrm{BaSO}_{4}, \mathrm{Mg}(\mathrm{OH})_{2}, \mathrm{BaCO}_{3}, \mathrm{CaCO}_{3}$, yang bernilai komersial. Dengan diolahnya konsentrat desalinasi dengan konsep ZDD hingga menjadi produk komersial, maka salinitas konsentrat menjadi nol dan material insoluble yang tersisa dapat dipisahkan.

\section{DAFTAR PUSTAKA}

[1]. "Pemerintah Kabupaten Bangka", www.bangka.go.id/content.php? , diakses 24 Juni 2012.

[2]. SITI ALIMAH, "Studi Pembuangan Konsentrat Desalinasi", Jurnal Pengembangan Energi Nuklir, PPEN, BATAN, Volume 12 Nomor 2, Desember 2010.

[3]. TAMIM YOUNOS, "Enviromental Issues of Desalination", Journal of Comtemporary Water Research and Education", Page 11-18, December 2005.

[4]. SIFT, AHP., et.all., "Zero Discharge Waste Brine Management for Desalination Plants", Desalination Research and Development Program Report No. 89, Desember 2002.

[5]. SITI ALIMAH, "Studi Penukar Panas Antara (IHX) PLTN PWR Kopling Desalinasi MED", Prosiding Seminar Nasional Teknologi Energi Nuklir VII, PKSEN, BATAN, 2014.

[6]. IAEA, "Enviromental Impact Assessment of Nuclear Desalination", IAEA- TECDOC 1642, Vienna 2010.

[7]. "Desalinasi Air Garam”, http://majarimagazine.com/2009/05/desalinasi-air-garam/, diakses Desember 2012

[8]. TULARAM, GA., et.all., "Enviromental Concern of Desalinating Seawater Using Reverse Osmosis", Journal of Environmental Monitoring, June 2007.

[9]. LATEMAN, S., et.all., "Enviromental Impact and Impact Assessment of Seawater Desalination", Journal Desalination, Page 1-15, March 2007.

[10]. "Desalination : A National Perspective", http://waterwebster.org/documents/ NRCDesalination report_000.pdf

[11]. "Zero Discharge Seawater Desalination : http://www.usbr.gov/research/AWT/ reportpdfs/report111.pdf, diakses Juli 2012

[12]. http://www.patentlens.net/patentlens/patents.html?patnums=WO_2004_041731_A1\& language=\&\#tab_1, Process And Apparatus For The Treatment ff Saline Water, diakses Juni 2012.

[13]. TEGUH ARIYANTO, dkk. "Pra Rancangan Pabrik Garam Farmasi dari Garam Rakyat Kapasitas 40.000 ton/tahun" Forum Riset Industri Indonesia ke 3, 2011.

[14]. DEPARTMENT OF GEOGRAPHY, "Introduction to Hydrolog", Okanagan University College, 2011.

[15]. http://www.wiredchemist.com/chemistry/data/solubility-product-constants, Solubility Product Constants, Ksp, diakses Mei 2012. 